\title{
The Impact of an Acute Care Surgical Service on the Quality and Efficiency of Care Outcome Indicators for Patients with General Surgical Emergencies
}

\author{
Krista Hardy ${ }^{1}$, Jennifer Metcalfe ${ }^{1}$, Kathleen Clouston ${ }^{1}$, Ashley Vergis \\ 1. Surgery, St. Boniface Hospital, University of Manitoba, Winnipeg, CAN
}

Corresponding author: Kathleen Clouston, kclouston@sbgh.mb.ca

\section{Abstract \\ Background}

Acute care surgery (ACS) models address high volumes of emergency general surgery and emergency room (ER) overcrowding. The impact of ACS service model implementation on the quality and efficiency of care (EOC) outcomes in acute appendicitis (AA) and acute cholecystitis (AC) cohorts was evaluated.

\section{Methods}

A retrospective chart review $(\mathrm{N}=1,229)$ of adult $\mathrm{AA}$ and $\mathrm{AC}$ patients admitted prior to (pre-ACS; $\mathrm{n}=507$; three hospitals; 2007) and after regionalization (R-ACS; $\mathrm{n}=722$; one hospital; 2011).

\section{Results}

R-ACS time to ER physician assessment was significantly longer for AA (3.4 \pm 2.3 versus $2.4 \pm 2.6 \mathrm{hr} ; \mathrm{p} \leqslant$ $0.001)$. Surgical response times $(1.3 \pm 1.2$ vs $2.6 \pm 4.3 \mathrm{hr}$ for AA; $1.8 \pm 1.5 \mathrm{vs} 4.1 \pm 5.0 \mathrm{hr}$ for AC; $\mathrm{p} \leqslant 0.0001)$ and acquisition of imaging $(4.1 \pm 4.1 \mathrm{vs} 6.9 \pm 9.9 \mathrm{hr}$ for AA, $\mathrm{p} \leqslant 0.0001 ; 7.8 \pm 1.9 \mathrm{vs} 13.2 \pm 18.5 \mathrm{hr}$ for AC, $\mathrm{p} \leqslant 0.008)$ occurred significantly faster with R-ACS. R-ACS resulted in a significant increase in night-time appendectomies ( $21.7 \%$ vs $11.1 \%$; $\leqslant \leqslant 0.002$ ), perforated appendices ( $29.1 \%$ vs $18.9 \% ; p \leqslant 0.006)$, 30-day readmissions $(4.56 \%$ vs $0.82 \% ; \mathrm{p} \leqslant 0.01)$, and lower rate of intraoperative complications for AC patients ( $2.78 \%$ vs $7.69 \% ; \mathrm{p} \leqslant 0.02)$.

\section{Conclusions}

Despite the increased volume of patients seen with the implementation of R-ACS, surgical assessments and diagnostic imaging were significantly more prompt. EOC measures were maintained. Worse AA outcomes highlight areas for improvement in delivering R-ACS.

Received 06/06/2019

Review began 06/10/2019 Review ended 06/27/2019 Published 06/29/2019

๑) Copyright 2019

Hardy et al. This is an open access article distributed under the terms of the Creative Commons Attribution License CC-BY 3.0., which permits unrestricted use, distribution, and reproduction in any medium, provided the original author and source are credited.
Categories: Emergency Medicine, General Surgery, Quality Improvement

Keywords: acute care surgery service, retrospective chart review, patient and health system outcomes, acute appendicitis, acute cholecystectomy

\section{Introduction}

General surgeons face the challenge of managing high volumes of emergency general surgery (EGS) patients with advanced age and increasingly complex conditions [1]. Often, urgent intervention to prevent rapid patient deterioration is necessary [2] and compounded by limits in emergency department (ED) access due to overcrowding. Such delays may be associated with higher rates of major complications and death [3]. ACS was developed as an extension of trauma surgery services, including emergency surgery while maintaining operative skills through increased operative volume. It also benefited patients by improving the timeliness of care [4]. In Canada, the impetus to create acute care surgery services (ACS) also arose from the high volume of EGS cases, increasing surgeon sub-specialization, facilitation of the separation of elective practice from emergency surgery cases, and the regionalization of subspecialty surgical care [5].

An organized ACS team is proposed to facilitate the prompt, comprehensive, evidence-based care of EGS patients, leading to improved efficiency of care (EOC) measures, reduced complications, and decreased length of stay and cost [6-16]. A dedicated service with protected daytime operating and a surgeon relieved of elective duties should facilitate more daytime operating $[13-14,16]$ and potentially minimize human error related to surgeon fatigue [7].

There are 13 ACS services in Canada with significant variation in organization and function [1,5]. The lack of standardization for ACS outcome measures and reporting makes comparisons among ACS services challenging [17-18]. Acute appendicitis (AA) and acute cholecystitis (AC) are the most common EGS 
The lack of agreement and utilization of standard metrics to report EOC and patient outcomes within ACS service delivery, in addition to the high degree of variability in the definitions of each variable, make reporting and comparisons challenging. Standardization and consensus is required among ACS surgeons (and the health care teams/stakeholders involved in delivering care) to create an organized system of data capture and analysis to establish national standards for ACS service implementation and delivery, including support for evidence-based practice, quality improvement initiatives, as well as research, training/education, and innovation. Metcalfe et al. [17] reported that approximately $27 \%(6 / 22)$ of studies of ACS implementation provided surgical response time and included five different definitions for this metric. Time to operating room was reported in $91 \%$ (20/22) of studies, with between five to seven distinct definitions while LOS was reported in $86 \%$ of studies with three separate definitions.

Three Winnipeg hospitals’ EGS services were consolidated into a regionalized ACS service (R-ACS) [6], resulting in a $221 \%$ increase in patient volume. Approximately 56\% of ACS service in-patient admissions are transferred from another institution; 39 provincial hospitals (five within and 34 outside Winnipeg), as well as 19 other institutions (nursing stations, personal care homes, health centers, home care/physician's offices). Interhospital transfer has been shown to impact the surgical quality and patient outcome metrics, as well as the utilization of hospital and health system delivery resources [19-20].

The average annual number of cases admitted to the ACS service was 4,024; depending on the hospital, between $32 \%$ to $53 \%$ are medically managed while $47 \%$ to $68 \%$ are surgically managed. Per capita, the Winnipeg ACS service receives approximately 566 ACS admissions per 100,000 people. Research evaluating whether R-ACS in Winnipeg leads to improved efficiency and patient outcomes is crucial in facilitating evidence-based care, creating benchmark standards, and highlighting areas for system improvement. The study objective was to determine the impact of implementing a regionalized ACS on EOC and patient outcomes for common general surgical emergencies (acute appendicitis and acute cholecystitis).

\section{Materials And Methods}

A retrospective chart review of AA and AC patients was performed to compare EOC and patient outcome measures between the Pre-ACS and R-ACS cohorts (University of Manitoba Health Research Ethics Board number H2012:166; HS15311; individual institutional ethics approvals obtained). A flow diagram of the patient chart extraction process is provided in Figure 1. AA ( $n=244$ and $n=329$ for the Pre-ACS and R-ACS groups, respectively) and AC ( $\mathrm{n}=157$ and $\mathrm{n}=254$ for the Pre-ACS and R-ACS groups, respectively) diagnoses were chosen, as they are the most common reasons for EGS admission [7] with standard, measurable points of care. Adult (>17 years) patients diagnosed with AA or AC during the January to December (2007) and January to December (2011) study periods were included. Charts were identified by diagnostic and procedural ICD-10 codes and included regardless of whether or not they underwent an operation during admission. Exclusion criteria included patients who were admitted to a service other than general surgery or ACS, admission with a diagnosis not meeting the case definition, and patients undergoing appendectomy or cholecystectomy as an elective procedure or secondary to another operation. Biliary cases with a diagnosis other than acute cholecystitis were excluded (including gallstones, choledocholithiasis, and biliary colic) due to the significant variability in course of care and surgical decision-making.

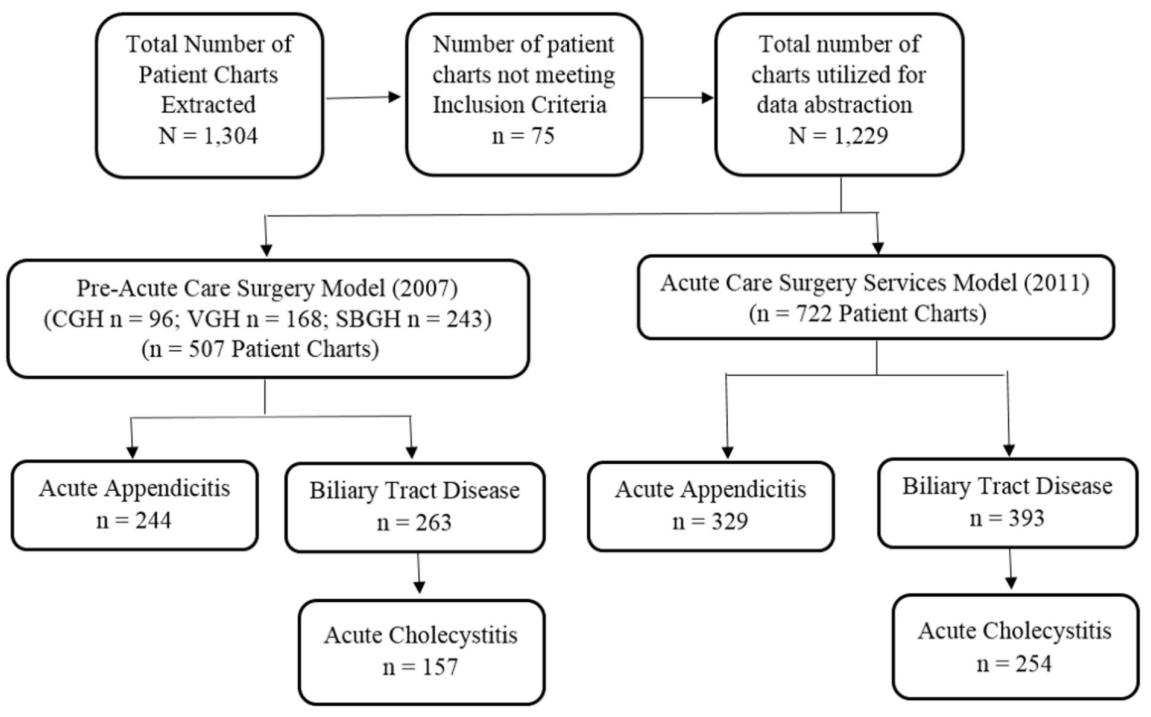

FIGURE 1: Flow Diagram of Patient Chart Extraction Process, Number of Charts for Data Abstraction, and Study Results for the Pre-Acute Care 
Three hospitals in Winnipeg (Canada) contributed to this investigation: St. Boniface General Hospital (tertiary academic), Concordia General Hospital (urban community), and Victoria General Hospital (urban community). The Pre-ACS implementation period from January 1 to December 31, 2007, represented the traditional "on-call" model. This cohort included patients admitted emergently to the general surgery services of each hospital. The ACS service was implemented in 2008 and the regionalized or R-ACS study period was January 1 to December 31, 2011. This year was selected for R-ACS to represent a stable mature system that had been functioning for several years. In the regionalized model, patients from the Concordia and Victoria General Hospitals were routinely transferred to St. Boniface for evaluation. During this period, there was a dedicated weekday operating room time designated for emergency general surgery patients (1000 hrs to $1530 \mathrm{hrs).} \mathrm{Each} \mathrm{of} \mathrm{the} \mathrm{three} \mathrm{Pre-ACS} \mathrm{hospitals} \mathrm{had} \mathrm{their} \mathrm{own} \mathrm{'on-call'} \mathrm{roster} \mathrm{servicing} \mathrm{their}$ emergency department that acted independently and was staffed by a single surgeon (urban community sites) or a single surgeon/resident team (SBGH; tertiary). The surgeon/resident team took EGS calls, had regular elective duties, and completed their EGS responsibilities on an ad hoc basis.

Patient baseline demographics were recorded, including age at admission (years), gender, body mass index (BMI), previous laparotomy, smoking status, medications (anticoagulants and steroids), and the following five comorbidities: (1) Cardiac (ischemic heart disease, arrhythmia, congestive heart failure), (2) Respiratory (chronic obstructive pulmonary disease (COPD), asthma), (3) Bleeding diathesis (bleeding disorder, cirrhosis), (4) Endocrine (diabetes mellitus), (5) Hematology (deep vein thrombosis, pulmonary embolism). The existence of these comorbidities was important to document, as they may impact the peri-operative variables under investigation. Data for the Pre-ACS and R-ACS periods were collected for multiple EOC time points along the patient trajectory (admission to discharge), allowing a retrospective temporal trend analysis of the data (similar to interrupted time series analysis). Both date and time were recorded for the general surgery/ACS consultation (origin hospital), triage/assessment room, emergency room physician assessment, surgical consultation, surgical assessment, hospital admission, and hospital discharge EOC variables. Date, time, and location were recorded for the radiology (ultrasound, computed tomography, and magnetic resonance imaging) and non-operative intervention (endoscopic retrograde cholangiopancreatography (ERCP), percutaneous drain insertion, gastroscopy, and colonoscopy) EOC variables. Start time (time of surgical incision), end time (skin closure), time of day (day (07:00-15:59); evening (16:00-23:59), or night (00:00-06:59)), surgical procedure type/classification (laparoscopic, open or converted) were recorded for the operative intervention EOC variable. The EOC time variables are depicted in Figure 2. Five baseline hospital admission variables were measured, including (1) admission diagnosis, (2) origin hospital (if transferred), (3) Regional Health Authority of the origin hospital, (4) admission hospital and service, and (5) previous admissions information for the same diagnosis.

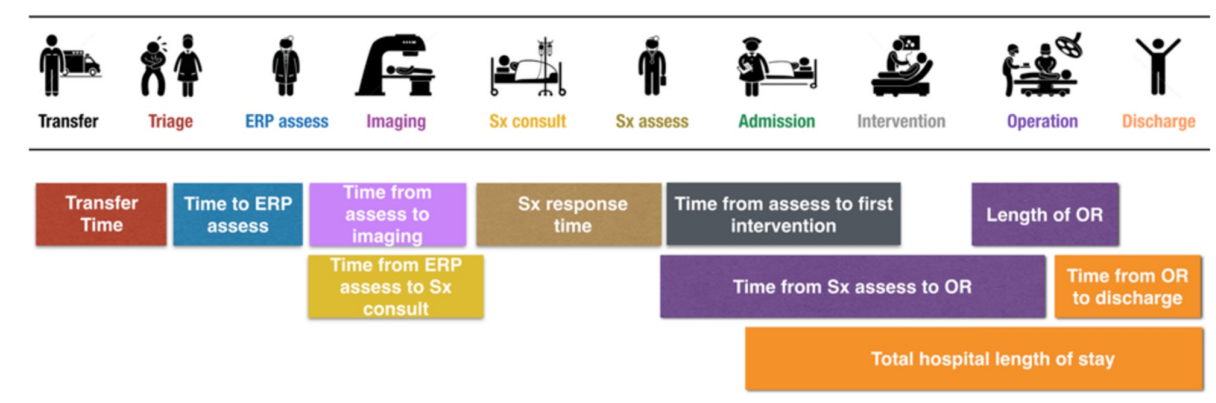

\section{FIGURE 2: Efficiency of Care Time Variables}

*ERP, emergency room physician; Sx, Surgical assessment; OR, operating room.

The patient outcome variables measured included intra-operative, intervention-related, and postoperative complications, time to operating room, total length of stay (LOS), 30-day hospital readmission rate, 30-day emergency room (ER) visits, risk of perforated appendicitis, and pathology for appendectomy and cholecystectomy specimens. Post-operative complications were graded according to the Clavien-Dindo Classification System on a scale of I through V; minor grades I to II, major grades III to V [9].

Study-specific reference documents, specifying the chart location for each outcome variable being extracted, facilitated reproducible and uniform data extraction (Supplemental Files 1, 2, and 3 in the Appendix). If the variable was not found in the pre-specified location, it was recorded as "not specified." Uniform and consistent data extraction methods were facilitated through joint data extracted by two research team 
members (HG and JM); 50 charts at both Concordia and Victoria General Hospitals. Where differences in assessment existed, discussion and resolution were attained and, if required, arbitrated by KH. SAS procedures were utilized to handle missing data. For data missing completely at random, listwise deletion was used (the number of missing values was low). Data missing at random were dealt with through imputation.

A sample size/power calculation was not performed for this research study, as all of the charts for each cohort (Pre-ACS and R-ACS) for both the acute appendicitis (AA) and acute cholecystitis (AC) groups were retrieved and reviewed.

Data were analyzed with SAS ${ }^{\circledR}$ statistical software (SAS Institute, North Carolina, US). The AA and AC groups within the Pre-ACS and R-ACS cohorts were analyzed separately. Continuous data were analyzed with the two-tailed student's t-test. Chi-square tests were used to test categorical variables; Fisher's exact test was used if sample numbers were small $(<5)$. A logistic regression analysis was performed for postoperative complications, readmissions, risk of perforated appendicitis, time to OR, and total length of stay (LOS). Logistic regression model covariates were chosen by a clinical decision and the backward selection method. Age and gender were deemed significantly relevant and included in all logistic models. The backward selection method started with all covariates included in the analysis plan. Variables were deleted from the model based on p-value; $p$-values $>0.02$ were deleted. Cook's D statistics were plotted for each regression model to determine the influence of each observation. Tolerance values to test for multicollinearity among the covariates was performed and absence confirmed among the variables tested; all tolerance values were greater than 0.1 and had Variance Inflation Factor (VIF) less than 10.

\section{Results}

Data were extracted from a total of 1,229 charts and represents two cohorts: the Pre-ACS ( $\mathrm{n}=507)$ and R-ACS $(\mathrm{n}=722)$ cohorts. The Pre-ACS cohort includes patients from three hospitals $(\mathrm{n}=243 \mathrm{SBGH}, \mathrm{n}=168 \mathrm{VGH}, \mathrm{n}=96$ $\mathrm{CGH}$ ). The AA and AC procedures were utilized to compare the Pre-ACS and ACS surgical outcomes. Table 1 outlines the baseline demographic variables for both AA and AC groups for the Pre-ACS versus R-ACS cohorts. No significant differences were found in the baseline demographic variables between the Pre-ACS and R-ACS cohorts for AC. All baseline demographic variable outcomes were similar for AA patients in both the Pre- and R-ACS cohorts, except mean age at admission, which was significantly higher in the R-ACS group as compared to the Pre-ACS group $(39.26 \pm 16.63$ vs $36.35 \pm 15.05 ; \mathrm{p}<0.03)$ and a significantly larger percentage of patients in the R-ACS cohort had a previous midline laparotomy compared to the Pre-ACS cohort (5.18\% vs $1.23 \%$; $\mathrm{p}<0.01$ ). The presence of the five comorbidities was similar between the Pre- and RACS cohorts for both the AA and AC groups (Table 2). 


\section{Cureus}

\begin{tabular}{|c|c|c|c|c|c|c|}
\hline \multirow{2}{*}{ Variable } & \multicolumn{3}{|l|}{ Acute Appendicitis } & \multicolumn{3}{|l|}{ Acute Cholecystitis } \\
\hline & Pre-ACS $(n=244)$ & R-ACS ( $=329)$ & $\mathrm{p}$-value & Pre-ACS $(n=157)$ & R-ACS (n = 254) & $p$-value \\
\hline Mean Age (SD) & $36.4(15.1)$ & $39.3(16.6)$ & 0.03 & $54.8(18.4)$ & $51.3(18.2)$ & 0.06 \\
\hline \multicolumn{7}{|l|}{ Gender (\%) } \\
\hline Male & 51.2 & 52.4 & \multirow{2}{*}{0.7} & 37.8 & 41.3 & \multirow{2}{*}{0.5} \\
\hline Female & 48.8 & 47.6 & & 62.2 & 58.7 & \\
\hline Mean BMI (SD) & $27.5(6.2)^{1}$ & $26.4(5.4)^{2}$ & 0.06 & $29.5(6.45)^{3}$ & $30.5(6.78)^{4}$ & 0.2 \\
\hline \multicolumn{7}{|c|}{ Previous Laparotomy (\%) } \\
\hline No & 98.8 & 94.8 & \multirow{2}{*}{$0.01^{*}$} & 95.5 & 91.7 & \multirow{2}{*}{0.1} \\
\hline Yes & 1.2 & 5.2 & & 4.5 & 8.3 & \\
\hline \multicolumn{7}{|c|}{ Select Medications (\%) } \\
\hline No & 97.5 & 98.8 & \multirow{2}{*}{$0.3^{*}$} & 91.7 & 94.8 & \multirow{2}{*}{0.2} \\
\hline Yes & 2.5 & 1.2 & & 8.3 & 5.2 & \\
\hline
\end{tabular}

TABLE 1: Baseline Demographics for Acute Appendicitis (AA) and Acute Cholecystitis (AC) in the Pre-ACS (2007) versus Regionalized ACS (2011) Cohorts

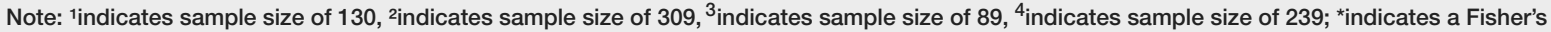
Exact Test was used; R-ACS is Regionalized Acute Care Surgery (ACS); Select medications are steroids and anticoagulants. 


\section{Cureus}

\begin{tabular}{|c|c|c|c|c|c|c|}
\hline \multirow{2}{*}{ Comorbidity } & \multicolumn{3}{|c|}{ Acute Appendicitis } & \multicolumn{3}{|c|}{ Acute Cholecystitis } \\
\hline & Pre-ACS (2007) & R-ACS (2011) & $\mathrm{p}$-value & Pre-ACS (2007) & R-ACS (2011) & $\mathrm{p}$-value \\
\hline \multicolumn{7}{|l|}{ Cardiac } \\
\hline Yes & 3.3 & 2.7 & \multirow{2}{*}{0.7} & 13.6 & 10.1 & \multirow{2}{*}{0.4} \\
\hline No & 96.7 & 97.3 & & 86.4 & 89.9 & \\
\hline \multicolumn{7}{|l|}{ Respiratory } \\
\hline Yes & 2.9 & 3.7 & \multirow{2}{*}{0.6} & 4.6 & 2.1 & \multirow{2}{*}{0.3} \\
\hline No & 97.1 & 96.4 & & 95.5 & 97.9 & \\
\hline \multicolumn{7}{|c|}{ Bleeding Diathesis } \\
\hline Yes & 0.8 & 0.0 & \multirow{2}{*}{$0.2^{*}$} & 0.00 & 1.1 & \multirow{2}{*}{0.5} \\
\hline No & 99.2 & 100.0 & & 100.0 & 98.9 & \\
\hline \multicolumn{7}{|l|}{ Hematology } \\
\hline Yes & 1.2 & 0.3 & \multirow{2}{*}{$0.3^{*}$} & 0.9 & 0.53 & \multirow{2}{*}{$1.00^{*}$} \\
\hline No & 98.8 & 99.7 & & 99.1 & 99.5 & \\
\hline \multicolumn{7}{|l|}{ Endocrine } \\
\hline Yes & - & - & \multirow{2}{*}{ - } & 8.2 & 11.6 & \multirow{2}{*}{0.3} \\
\hline No & - & - & & 91.8 & 88.4 & \\
\hline
\end{tabular}

\section{TABLE 2: Comorbidities for Acute Appendicitis (AA) and Acute Cholecystitis (AC) in the Pre-ACS (2007) versus Regionalized ACS (2011) Cohorts}

*indicates a Fisher's Exact Test was used.

EOC and patient outcome measures were compared between the Pre-ACS and R-ACS cohorts for both the AA and AC patient groups (Table 3 and Table 4; Figure 3 and Figure 4). For both the AA and AC diagnoses, the RACS cohort had a significantly higher percentage of hospital transfers as compared to direct admissions ( $\mathrm{AA}=67.1 \%$ vs $14.3 \%, \mathrm{p}<0.0001 ; \mathrm{AC}=59.5 \%$ vs $14.2 \%, \mathrm{p}<0.0001$ ) and laparoscopic procedures (versus open; $\mathrm{AA}=97.8 \%$ vs $80.6 \%, \mathrm{p}<0.0001 ; \mathrm{AC}=100 \%$ vs $94.4 \%, \mathrm{p}<0.0001)$. The mean length of time for $\mathrm{AA}$ and $\mathrm{AC}$ procedures were significantly longer in the R-ACS service cohort as compared to the Pre-ACS cohort (AA=62.8 vs 55.5 minutes, $\mathrm{p}<0.001 ; \mathrm{AC}=96.7$ vs 82.5 minutes, $\mathrm{p}<0.0001$ ). Significantly fewer R-ACS cohort AA patients had their surgeries during the evening (16:00 to 23:59) as compared to the Pre-ACS cohort AA patients $(50.3 \%$ vs $63.2 \%$, p $<0.002)$ while a significantly larger percentage of R-ACS patients, as compared to Pre-ACS patients, had their surgery at night (00:00 to $06: 59 ; 21.7 \%$ vs $11.1 \%, \mathrm{p}<0.002)$. A similar number of AA patients had their surgeries during the day in both the Pre-ACS and ACS cohorts. No differences in surgical time of day existed between the cohorts for AC patients. For non-operative interventions, three percutaneous drain insertions were performed (two of the interventions involving the same patient) in the Pre-ACS AA group. One patient in the R-ACS AA patient group was managed non-operatively (missed appendicitis with phlegmon). For both the Pre- and R-ACS cohorts, ERCP was the most common nonoperative intervention performed in the AC patient group and did not differ between the cohorts (22.4 versus $15.3 \%$; $=0.08$ ). In addition, no significant differences were found in the frequency of operation for acute cholecystitis among the Pre-ACS and R-ACS cohorts (90.3\% versus 94.4\%, $\mathrm{p}=0.10$ ). 


\section{Cureus}

\begin{tabular}{|c|c|c|c|c|c|c|}
\hline \multirow{2}{*}{ Variable $^{1}$} & \multicolumn{3}{|c|}{ Acute Appendicitis (AA) ${ }^{2}$} & \multicolumn{3}{|c|}{ Acute Cholecystitis (AC) ${ }^{3}$} \\
\hline & $\begin{array}{l}\text { Pre-ACS Mean } \\
\text { Hours (SD) }\end{array}$ & $\begin{array}{l}\text { R-ACS Mean } \\
\text { Hours (SD) }\end{array}$ & $\mathrm{p}$-value & $\begin{array}{l}\text { Pre-ACS Mean } \\
\text { Hours (SD) }\end{array}$ & $\begin{array}{l}\text { R-ACS Mean } \\
\text { Hours (SD) }\end{array}$ & $\mathrm{p}$-value \\
\hline Transfer Time & $2.1(1.6)$ & $2.7(2.1)$ & 0.2 & $4.1(3.1)$ & $3.3(3.0)$ & 0.3 \\
\hline Total LOS & $63.4(99.1)$ & $52.2(75.1)$ & 0.1 & $116.0(129.3)$ & $93.3(144.4)$ & 0.1 \\
\hline Time to ERP assess & $2.4(2.6)$ & $3.4(2.3)$ & 0.001 & $2.6(3.6)$ & $3.1(2.4)$ & 0.2 \\
\hline Time to Sx assess & $2.6(4.3)$ & $1.3(1.2)$ & $<0.0001$ & $4.1(5.0)$ & $1.8(1.5)$ & $<0.0001$ \\
\hline $\begin{array}{l}\text { Time from ERP or Sx assess to } \\
\text { first imaging }\end{array}$ & $6.9(9.9)$ & $4.1(4.1)$ & $<0.0001$ & $13.2(18.5)$ & $7.8(11.9)$ & 0.01 \\
\hline Time from $S x$ assess to $O R$ & $6.8(7.1)$ & $8.0(6.3)$ & 0.03 & $32.3(31.5)$ & $29.9(27.8)$ & 0.4 \\
\hline Time from OR to discharge & $53.0(90.8)$ & $45.3(74.9)$ & 0.3 & 72.6 (92.2) & $51.6(118.5)$ & 0.1 \\
\hline $\begin{array}{l}\text { Time from Sx assess to first } \\
\text { intervention }\end{array}$ & - & - & - & $127.8(501.6)$ & $24.0(28.1)$ & 0.1 \\
\hline
\end{tabular}

TABLE 3: Efficiency of Care Outcome Variables for Acute Appendicitis and Acute Cholecystitis in the Pre-ACS (2007) versus Regionalized ACS (2011) Cohorts

${ }^{1}$ Abbreviations: LOS=length of stay; ERP=emergency room physician; Sx=surgeon; assess=assessment; OR=operation; min=minutes; SD=standard deviation; R-ACS=Regionalized Acute Care Surgery

${ }^{2}$ Sample sizes varied between the cohorts for each outcome variable assessed for AA. Transfer time ( $n=32$ and 213 for Pre-ACS and R-ACS, respectively); Total LOS ( $n=243$ and 329 for Pre-ACS and R-ACS, respectively); Time to ERP assess ( $n=197$ and 109 for Pre-ACS and R-ACS, respectively); Time to Sx assess ( $n=205$ and 307 for Pre-ACS and R-ACS, respectively); Time from ERP or Sx assess to first imaging ( $n=146$ and 181 for Pre-ACS and R-ACS, respectively); Time from Sx assess to OR ( $n=230$ and 328 for Pre-ACS and R-ACS, respectively); Time from OR to discharge ( $\mathrm{n}=238$ and 328 for Pre-ACS and R-ACS, respectively).

${ }^{3}$ Sample sizes varied between the cohorts for each outcome variable assessed for AC. Transfer time ( $n=23$ and 153 for Pre-ACS and R-ACS, respectively); Total LOS ( $n=175$ and 267 for Pre-ACS and R-ACS, respectively); Time to ERP assess ( $n=144$ and 105 for Pre-ACS and R-ACS, respectively); Time to Sx assess ( $n=144$ and 244 for Pre-ACS and R-ACS, respectively); Time from ERP or Sx assess to first imaging ( $n=116$ and 122 for Pre-ACS and R-ACS, respectively); Time from Sx assess to OR ( $n=151$ and 252 for Pre-ACS and R-ACS, respectively); Time from OR to discharge ( $n=158$ and 252 for Pre-ACS and R-ACS, respectively); Time from Sx assess to first intervention ( $n=27$ and 61 for Pre-ACS and R-ACS, respectively).

Variable

Risk of Perforated Appendicitis

Intra-Operative Complication Rate

Post-Operative Complication Rate by Grade

Grades I \& II

Grades III, IV, V

30-Day Readmission Rates

30-Day Emergency Department Visits
Acute Appendicitis (AA)

Pre-ACS n (\%)

40 (18.9)

$1(0.4)$

20 (8.2)

4 (1.6)

$2(0.8)$

$8(3.3)$
Acute Cholecystitis (AC)

Pre-ACS n (\%) R-ACS n (\%) p-value $94(29.1) \quad 0.006 \quad-$

$3(0.9) \quad 0.9 \quad 12(7.7)$

7 (2.8)

0.02

TABLE 4: Patient Outcome Variables for Acute Appendicitis and Acute Cholecystitis in the PreACS (2007) versus Regionalized ACS (2011) Cohorts

${ }^{\star}$ Fisher's Exact Test was used.

ACS: Acute Care Surgery 


\section{Cureus}

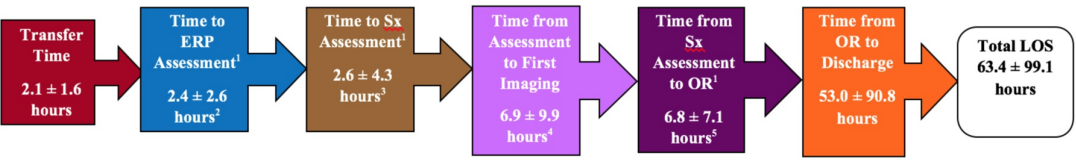

(a) Pre-Acute Care Surgery Services Timeline (2007) - Acute Appendicitis (AA)

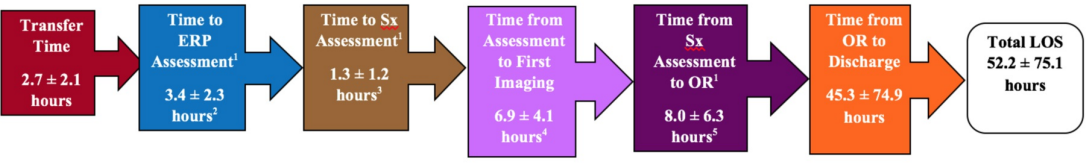

(b) Regionalized-Acute Care Surgery Services Timeline (2011) - Acute Appendicitis (AA)

FIGURE 3: Time Line by Stage Between ER Arrival and Operative Intervention for Pre- and Regionalized ACS Services Cohorts: Acute Appendicitis (AA)

${ }^{1}$ ERP, emergency room physician; Sx, Surgical assessment; OR, operating room; ACS: acute care surgery. ${ }^{2} p<0.001 ; 3 p<0.0001 ;{ }^{4} p<0.0001 ;{ }^{5} p<0.03$

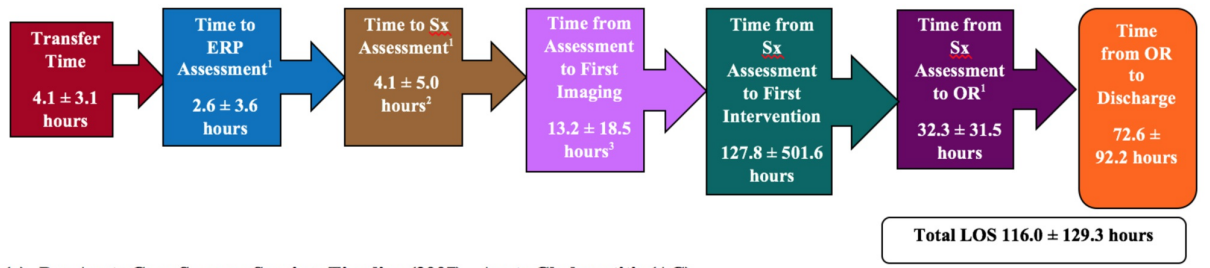

(a) Pre-Acute Care Surgery Services Timeline (2007) - Acute Cholecystitis (AC)

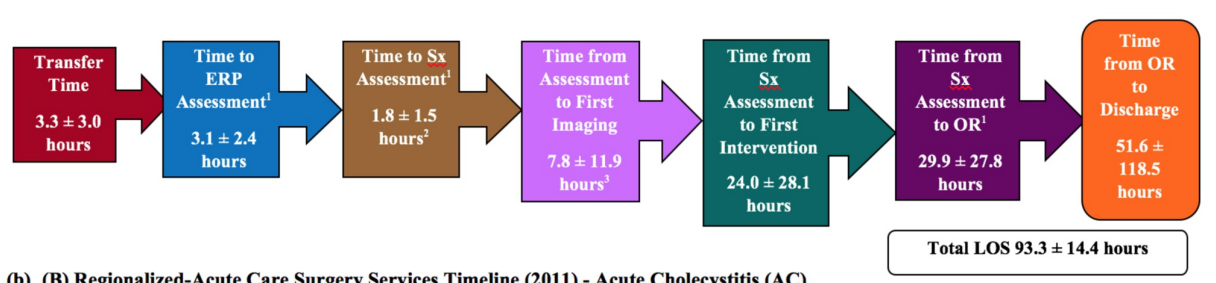

(b) (B) Regionalized-Acute Care Surgery Services Timeline (2011) - Acute Cholecystitis (AC)

\section{FIGURE 4: Time Line by Stage Between ER Arrival and Operative Intervention for Pre- and Regionalized ACS Services Cohorts: Acute} Cholecystitis (AC)

${ }^{1}$ ERP, emergency room physician; Sx, Surgical assessment; OR, operating room; ACS: acute care surgery.

${ }^{2} p<0.0001 ; 3 p<0.01$

For patients with AA, regionalization of the ACS service did not result in significant improvements from the Pre-ACS service for transfer time, time from operating room to discharge, or total length of stay (LOS). Time to emergency room physician (ERP) for AA patients was significantly higher in the R-ACS as compared to the Pre-ACS cohort ( $3.4 \pm 2.3$ hours vs $2.4 \pm 2.6$ hours, $\mathrm{p}<0.001$ ). However, these same patients experienced a significantly shorter time to surgical assessment/surgical response time $(1.3 \pm 1.2$ hours vs $2.6 \pm 4.3$ hours, $\mathrm{p}<0.0001)$ as well as time from ERP or surgical assessment to imaging ( $4.1 \pm 4.1$ hours vs $6.9 \pm 9.9$ hours, $\mathrm{p}<0.0001$ ). In addition, the frequency of pre-operative imaging (ultrasound (US), computed tomography (CT), magnetic resonance imaging (MRI)) was significantly higher among R-ACS AA patients as compared to Pre-ACS AA patients (93.3\% vs 70.1\%; p 0.0001). Similarly, the R-ACS service significantly reduced both time to surgical assessment/surgical response time $(1.8 \pm 1.5$ hours vs $4.1 \pm 5.0$ hours, $p<0.0001)$ and time from ERP or surgical assessment to imaging for those patients with AC ( $7.8 \pm 1.9$ vs $13.2 \pm 18.5$, $\mathrm{p}<0.0001)$. 
All other EOC outcome variables were unaffected under R-ACS services. Data collected from multiple time points pre- and post-ACS implementation were used to retrospectively assess for temporal trends in the data, similar to an interrupted time series analysis. Evaluation of length of stay (LOS) for the AA and AC patient groups confirmed the absence of pre-existing trends towards decreased LOS prior to the implementation of ACS and no additional temporal trends were identified. Table 4 presents a summary of the findings for the patient outcome variables assessed. Under both the Pre-ACS and R-ACS service models, no differences were found in the time to the operating room for patients with perforated and non-perforated AA. However, the R-ACS cohort demonstrated significantly higher rates of risk of perforated appendicitis ( $29.1 \%$ vs $18.9 \%, \mathrm{p}<0.006$ ) and 30 -day readmission $(4.6 \%$ vs $0.8 \%, \mathrm{p}<0.01$ ) when compared to the Pre-ACS service model (Table 4). Risk of perforated appendicitis was based on appendectomy pathology findings. The frequency of intraoperative complications for AA patients was the same for both the Pre- and R-ACS service cohorts. For AC patients, the R-ACS service significantly reduced the rate of intraoperative complications ( $2.8 \%$ vs $7.7 \%, \mathrm{p}<0.02$ ). The frequency of 30-day emergency department visits was similar between the PreACS and ACS service models for both AA and AC patient groups.

Multivariate logistic regression demonstrated that post-operative complications and/or readmission for AA was associated with age, laparoscopic surgical procedure, transfer from another hospital, and admission to VGH or CGH as compared to SBGH (Table 5). Perforated appendicitis was associated with patient age and being transferred from another hospital versus direct admission (Table 6). Total LOS for AA patients was significantly associated with having a perforated appendix and open surgery versus laparoscopic surgery (Table 7). Time to operating room for AA patients was not significantly affected by age, gender, BMI, comorbidities, pre-operative imaging, and transfer to admitting hospital. For AC patients, the risk of postoperative complications and/or readmission was associated with age and having a laparoscopic procedure versus open surgery (Table 5). For AC patients, older age, presence of comorbidities, and longer time to operating room was associated with total hospital LOS and absence of a pre-operative intervention was the only covariate significantly associated with time to operating room (Table 8 ). 


\section{Cureus}

\begin{tabular}{|c|c|c|c|c|}
\hline \multirow[b]{2}{*}{ Variable } & \multicolumn{2}{|c|}{ Acute Appendicitis } & \multicolumn{2}{|c|}{ Acute Cholecystitis } \\
\hline & OR $(95 \% \mathrm{Cl})^{1}$ & $\mathrm{p}$-value & OR $(95 \% \mathrm{Cl})^{1}$ & $p$-value \\
\hline Age & $1.0(1.0,1.0)$ & 0.01 & $1.0(1.0,1.1)$ & 0.001 \\
\hline \multicolumn{5}{|l|}{ Gender } \\
\hline Male & $1.6(0.9,2.9)$ & 0.1 & $0.8(0.4,1.5)$ & 0.4 \\
\hline Female & reference & - & - & - \\
\hline \multicolumn{5}{|c|}{ Laparoscopic versus Open } \\
\hline Laparoscopic & $0.4(0.2,0.8)$ & 0.01 & $0.2(0.1,0.5)$ & 0.001 \\
\hline Open & reference & - & reference & - \\
\hline \multicolumn{5}{|c|}{ I ransfer versus Direct Admit } \\
\hline Transfer & $2.0(1.0,3.9)$ & 0.04 & - & - \\
\hline Direct & reference & - & - & - \\
\hline \multicolumn{5}{|c|}{ Admission Hospital $^{2}$} \\
\hline VGH/CGH & $2.4(1.1,5.1)$ & 0.03 & $0.5(0.2,1.2)$ & 0.1 \\
\hline SBGH & reference & - & reference & - \\
\hline \multicolumn{5}{|c|}{ Operating Room Time of Day } \\
\hline Day & - & - & reference & - \\
\hline Evening & - & - & $1.7(0.9,3.1)$ & 0.1 \\
\hline Night & - & - & $1.8(0.5,6.3)$ & 0.4 \\
\hline
\end{tabular}

TABLE 5: Logistic Regression Model for Appendicitis and Acute Cholecystitis Post-Operative Complications and Readmissions

${ }^{1} \mathrm{OR}=$ Odds Ratio; $\mathrm{Cl}=$ Confidence Interval.

${ }^{2}$ VGH= Victoria General Hospital; $\mathrm{CGH}=$ Concordia General Hospital; SBGH=St. Boniface General Hospital. 


\section{Cureus}

Variable

Age

Gender

Male

Female

Transfer versus Direct Admit

Transfer

Direct

Operating Room Time of Day

Day

Evening

Night
OR $(95 \% \mathrm{Cl})^{1}$

$1.0(1.0,1.0)$

p-value

$<0.0001$

$0.9(0.6,1.4)$

0.7

reference

$1.7(1.1,2.6)$

0.01

reference

reference

$0.7(0.4,1.15)$

0.2

$1.22(0.7,2.2)$

0.5

TABLE 6: Logistic Regression Model for Perforated Appendix

${ }^{1} \mathrm{OR}=$ Odds Ratio; $\mathrm{Cl}=$ Confidence Interval. 


\section{Cureus}

\begin{tabular}{|c|c|c|c|c|}
\hline Parameter 1,2 & Estimate & Standard Error & t Value & $\operatorname{Pr}>|t|$ \\
\hline Intercept & 5968.6 & 1487.0 & 4.0 & $<0.0001$ \\
\hline Age & 15.3 & 13.0 & 1.2 & 0.2 \\
\hline Gender - Female & -491.9 & 393.0 & -1.3 & 0.2 \\
\hline Gender - Male & 0.0 & . & . & . \\
\hline BMI & 0.8 & 35.0 & 0.02 & 1.0 \\
\hline Comorbidity - 0 & -1184.1 & 659.5 & -1.8 & 0.07 \\
\hline Comorbidity - 1 & 0.00 & . & . & . \\
\hline Perforated - 0 & -2419.2 & 462.0 & -5.2 & $<0.0001$ \\
\hline Perforated - 1 & 0.00 & . & . & . \\
\hline Type of OR procedure- Open & 2064.9 & 712.0 & 2.9 & 0.004 \\
\hline Type of OR procedure- Laparoscopic & 0.00 & . & . & . \\
\hline Time to OR & 0.6 & 0.5 & 1.1 & 0.3 \\
\hline Pre-operative intervention & 0.00 & . & . & . \\
\hline OR time of day - Day & -151.6 & 598.4 & -0.3 & 0.8 \\
\hline OR time of day - Evening & -462.8 & 541.1 & -0.9 & 0.4 \\
\hline OR time of day - Night & 0.00 & . & . & . \\
\hline Admission hospital - St. Boniface & -468.9 & 616.1 & -0.8 & 0.5 \\
\hline Admission hospital - VGH/CGH & 0.0 & . & . & . \\
\hline
\end{tabular}

\section{TABLE 7: Linear Regression Model for Hospital Length of Stay for Appendicitis}

${ }^{1} \mathrm{OR}=\mathrm{operating} \mathrm{room;} \mathrm{BMI:} \mathrm{body} \mathrm{mass} \mathrm{index.}$

${ }^{2} \mathrm{~N}=416$ observations; $\mathrm{r}^{2}=0.12$ (statistically significant). 


\section{Cureus}

\begin{tabular}{|c|c|c|c|c|}
\hline Parameter & Estimate & Standard Error & t Value & $\operatorname{Pr}>|t|$ \\
\hline Intercept & -4425.2 & 3798.0 & -1.2 & 0.3 \\
\hline Age & 114.6 & 25.7 & 4.5 & $<0.0001$ \\
\hline Gender - Female & 1205.3 & 811.8 & 1.5 & 0.1 \\
\hline Gender - Male & 0.0 & . & . & . \\
\hline BMI & 62.3 & 58.5 & 1.1 & 0.3 \\
\hline Comorbidity - 0 & -2936.1 & 1031.7 & -2.9 & 0.005 \\
\hline Comorbidity - 1 & 0.0 & . & . & . \\
\hline Type of $\mathrm{OR}^{1}$ procedure - Open & 3885.9 & 2124.9 & 1.8 & 0.07 \\
\hline Iype of UR procedure- LaparoscopIC & 0.0 & . & . & . \\
\hline Time to OR & 1.7 & 0.2 & 7.0 & $<0.0001$ \\
\hline Pre-operative intervention - 0 & 864.5 & 1129.5 & 0.8 & 0.5 \\
\hline Pre-operative intervention - 1 & 0.0 & . & . & . \\
\hline OR time of day - Day & -301.3 & 1790.7 & -0.2 & 0.9 \\
\hline OR time of day - Evening & -573.1 & 1771.8 & -0.3 & 0.8 \\
\hline OR time of day - Night & 0.0 & . & . & . \\
\hline Admission hospital - St. Boniface & 310.8 & 1244.2 & 0.3 & 0.8 \\
\hline Admission hospital - VGH/CGH & 0.0 & . & . & . \\
\hline
\end{tabular}

\section{TABLE 8: Linear Regression Model for Hospital Length of Stay for Acute Cholecystitis}

${ }^{1} \mathrm{OR}=$ operating room; BMI: body mass index

\section{Discussion}

This study assessed multiple EOC and patient-related outcomes for acute appendicitis and acute cholecystitis following the implementation of an R-ACS service in Winnipeg (Manitoba, Canada).

The R-ACS in Winnipeg resulted in not only some improvements in efficiency but also highlighted some areas for improvement. Time to ER physician assessment increased but time to surgical assessment/surgical response time and time to imaging decreased, indicating improved efficiency by a dedicated surgical team. With R-ACS, time to surgery was slightly increased for AA and did not improve for AC, highlighting the challenge of timely access to operating room resources for EGS patients even with the presence of a dedicated team. Time to discharge and LOS trended towards improvement. Postoperative care was already efficient under the traditional model, with the average LOS between 1.4 to 2.8 days (depending on simple versus complex appendectomy) for AA and 2.9 days for $\mathrm{AC}$, and improvements in this area were not demonstrated. Mean LOS for AA and AC from 2011 to 2017 were one and three days, respectively; one day less than the two additional Winnipeg hospitals performing these procedures. Multiple factors have been shown to impact LOS for AA patients, including time of presentation, perforation, and time of surgery [2122].

Currently, there are no established EOC benchmarks for common EGS diagnoses. The development of waittime benchmarks for common EOC measures is required to promote patient safety and inform program planning and evaluation.

Winnipeg has historically reported some of the longest ER wait times in Canada. The Canadian Institute for Health Information (CIHI) reported that four Winnipeg emergency departments were among the top five, with the longest wait times in Canada [23]. Multiple competing factors influence ERP assessment time, including ER patient flow, delays in admissions/ER clearance, and increased patient volumes. It is difficult to weigh the influence of various factors on the overall increase in ERP assessment time shown in this study without assessing the impact of each individual factor in detail. A comprehensive assessment of ER flow was beyond the scope of this study. However, significant restructuring of emergency care is underway in 
Winnipeg as part of an overall regional reorganization strategy. The impact of these changes will need to be assessed in the future.

We assessed intraoperative and perioperative patient outcomes related to AA and AC using commonly reported measures and classifications. Despite trainee involvement in the R-ACS services model, postoperative complications did not increase and there were significantly fewer intra-operative complications for AC and no change for AA. The same surgeons were involved in the pre-ACS and R-ACS cohorts but the reduction in complications for $\mathrm{AC}$ might be explained by increased experience with laparoscopy during the study period or possibly by the conduct of these procedures at a tertiary teaching institution. Variation in study definitions and outcome measures for EGS conditions are common throughout the scientific literature [17]. This makes a direct comparison among study results challenging. The standardization of common outcome measures both intraoperatively and perioperatively is necessary.

In this study, R-ACS resulted in a substantial increase in patient transfers, with $67.1 \%$ of appendectomies being transferred, as compared to only $14.3 \%$ in the Pre-ACS cohort. These patients were at higher risk of pathologically confirmed perforation and post-operative complications (or readmission). At 29\%, the R-ACS AA perforation rate is at the high end of published national rates of 20\%-30\% [24]. Other ACS studies have reported rates of $4.6 \%$ [14] and $17 \%[15]$ and a reduction of $10 \%$ [25]. Other studies have reported increased perforation rates with ACS service model implementation [15-16].

The risk of perforation might be influenced by delays in imaging or consultation requests at the origin hospital, inadequate initial care (antibiotics and fluid resuscitation), or as the result of more serious disease. We did not capture index hospital treatment and efficiencies as part of the current study. This would involve significant resources to review paper-based emergency department data at multiple sites, including transfers from outside of Winnipeg. This has been considered for future research.

Short delays in surgical intervention for AA are well-tolerated, with several studies reporting no increase in rupture when surgery is delayed until daytime hours [26-27]. One study reported the risk of rupture as negligible within the first 36 hours after symptom onset, with the risk rising $5 \%$ for each 12 -hour period with untreated symptoms [28]. R-ACS assessment of patients was faster but the number of daytime operations did not increase. This is likely as a result of competing surgical procedures, such as complex emergency bowel cases, which were more likely to be scheduled in daytime operating hours. In addition, fewer AA patients had evening surgery and more had night-time surgery with R-ACS. It is likely that appendectomies were performed at night out of necessity due to an increased volume of cases rather than the influence of surgeon remuneration. Within the ACS literature, most studies report increased daytime operating with ACS services while only one study found no increase in daytime operating [12-14]. Our logistic regression analysis did not show the operative time of day to be associated with patient outcomes. The increased 30day readmission rate for AA in the R-ACS cohort is likely associated with the increased rate of appendicular rupture. While some of these patients were treated with antibiotics, a significant number required either percutaneous or operative drainage.

Our study has a few limitations. Firstly, while transfer time was similar among the Pre-ACS and R-ACS cohorts, we did not capture the time spent at the referring hospital or treatments administered at the initial hospital. Secondly, our pre/post-study design lacked a concurrent control/comparison group, making it difficult to establish a cause and effect relationship between the intervention (ACS service implementation) and the outcomes measured. Thirdly, our results may be confounded by temporal and secular changes independent of the intervention. Surgeons who participated in EGS calls under the traditional (Pre-ACS) service model of care were the same as those involved in the R-ACS model and their laparoscopic experience increased over time.

Regression analysis showed that laparoscopic cases were associated with a decreased risk of postoperative complications, decreased readmissions, and shorter LOS. In the last five years, early surgical intervention for AC has been advocated and the hospitals providing the R-ACS service adopted this change. However, our results show no significant differences in time to OR or operative rate for AC between the Pre-ACS and RACS cohorts. Other temporal trends in practice patterns have not been captured by this study (favored antibiotic regimens, changes in antibiotic resistance). Also, competing procedures for the emergency OR were not assessed and could have impacted the R-ACS daytime OR measure.

The introduction of formal ACS services, along with changes in surgeon practice patterns across Canada, make the further regionalization of EGS likely, and its impact must be highlighted. As with other conditions with standardized protocols for care (myocardial infarctions or traumas) [28], pre-transfer guidelines, and standardized inter-hospital documentation could potentially improve the timeliness and quality of care. Some Canadian centers have developed clinical care pathways for patients with common EGS diagnoses [29]. A "Suspected Appendicitis Care Map" for adults has been developed to streamline the flow of patients from the ED to the OR [28].

\section{Conclusions}




\section{Cureus}

EGS patients are a uniquely challenging population, particularly prone to poor outcomes. Improved efficiency and quality of EGS care can significantly impact the emergency department, operating room, and hospital resources. We must continue to define, measure, and monitor specific outcomes in order to identify opportunities for improvement.

\section{Appendices}

\section{Supplemental File 1}

Data Quality Form - Demographic Variables

\begin{tabular}{|c|c|c|}
\hline Data Collected & Location in Chart & Quality \\
\hline Diagnosis & Face sheet & Electronic \\
\hline Origin hospital & Face sheet & Electronic \\
\hline RHA of origin hospital & $\mathrm{N} / \mathrm{A}$ & N/A \\
\hline Admission hospital/service & Face sheet & Electronic \\
\hline Age at admission & Face sheet & Electronic \\
\hline Gender & Face sheet & Electronic \\
\hline BMI & 2007: Anesthesia pre-op checklist 2011: EPR & $\begin{array}{l}\text { 2007: Hand-written 2011: } \\
\text { Electronic }\end{array}$ \\
\hline Comorbidities & ERP assessment Surgery consult Anesthesia consult & Handwritten \\
\hline Previous laparotomy & ERP assessment Surgery consult Anesthesia consult & Handwritten \\
\hline Smoking status & $\begin{array}{l}\text { ERP assessment Surgery consult Anesthesia consult } \\
\text { Anesthesia pre-op checklist }\end{array}$ & Handwritten \\
\hline Medications & DPIN & Electronic \\
\hline $\begin{array}{l}\text { Previous admission for same diagnosis } \\
\text { (date, location) }\end{array}$ & $\begin{array}{l}\text { ERP assessment Surgery consult Previous admissions listed } \\
\text { in chart }\end{array}$ & Handwritten 2011: EPR \\
\hline
\end{tabular}

TABLE 9: Supplemental File 1: Data Quality Form - Demographic Variables 


\section{Cureus}

Supplemental File 2

Data Quality Form - Intervention Variables

Data Collected

Non-Operative Interventions

Type

Date Performed And Time

Performed

Location Performed

Ordered By

Radiology

Type and Date Performed

Time Performed (Start time)

Location Performed

Ordered By

OR

Type

Date, Start Time, End Time

Length of OR and Time of Day

Drain/Conversion

Pathology
Location in Chart

Procedure note (eg, ERCP)

Nursing procedure record

Procedure note

Orders Consult Requisition

\section{Radiology report}

2007: Nursing notes, radiology technician reports (progress notes) 2011: Radiology report

Radiology report

Orders Requisition Radiology report

OR dictated report

Nursing OR record

Calculated

OR dictated report

Pathology report
Quality

Electronic

Hand-written

Electronic

2007: Handwritten 2011: EPR

Electronic

2007: Handwritten 2011: EPR

Electronic

2007: Handwritten 2011: EPR

Electronic

Handwritten

N/A

Electronic

Electronic

Excel Calculation: (((End_Date+End_Time)-(Start_Date+Start_Time) $\left.){ }^{\star} 24\right)^{\star} 60$

TABLE 10: Supplemental File 2: Data Quality Form - Intervention Variables 


\section{Cureus}

Supplemental File 3

Data Quality Form - Efficiency of Care

\begin{tabular}{|c|c|c|}
\hline Data Collected & Location in Chart & Quality \\
\hline Referring Facility & Face Sheet Photocopied notes from referring facility & Electronic \\
\hline Consult Date & Consult Nursing notes ACSS Transfer Form & Handwritten Handwritten Handwritten \\
\hline Consult Time & $\begin{array}{l}\text { Consult Nursing notes ERP assessment ACSS Transfer Form* } \\
\text { Fax time of transfer information }\end{array}$ & $\begin{array}{l}\text { Handwritten Handwritten Handwritten } \\
\text { Handwritten Electronic }\end{array}$ \\
\hline $\begin{array}{l}\text { Assessment Room } \\
\text { Date/Time }\end{array}$ & Nursing notes & Handwritten \\
\hline Triage Time & Triage sheet & Electronic \\
\hline $\begin{array}{l}\text { Admit Date, Admit Time, } \\
\text { Discharge Date }\end{array}$ & Face Sheet & Electronic \\
\hline Discharge Time & Face Sheet Nursing notes & Electronic Handwritten \\
\hline ERP Assess Date & ERP Assessment & Electronic \\
\hline ERP Assess Time & ERP Assessment Nursing Notes Orders & Handwritten Handwritten EPR (2011) \\
\hline ERP-Sx Consult Date & Consult & Handwritten, EPR (2011) \\
\hline ERP-Sx Consult Time & ERP Assessment Consult Nursing Notes & $\begin{array}{l}\text { Handwritten Handwritten, EPR }{ }^{\star} \text { (2011) } \\
\text { Handwritten }\end{array}$ \\
\hline Sx Assess Date & Consult & Handwritten \\
\hline Sx Assess Time & nsult Orders Nursing Note & $\begin{array}{l}\text { Handwritten Handwritten, EPR (2011) } \\
\text { Handwritten }\end{array}$ \\
\hline
\end{tabular}

*Inconsistently present; Excel Calculation: (((End_Date+End_Time)-(Start_Date+Start_Time))*24)*60

TABLE 11: Supplemental File 3: Data Quality Form - Efficiency of Care

\section{Additional Information \\ Disclosures}

Human subjects: Consent was obtained by all participants in this study. University of Manitoba Health Research Ethics Board issued approval HS15311 (H2012:166). This research was approved by the University of Manitoba Health Research Ethics Board. Animal subjects: All authors have confirmed that this study did not involve animal subjects or tissue. Conflicts of interest: In compliance with the ICMJE uniform disclosure form, all authors declare the following: Payment/services info: All authors have declared that no financial support was received from any organization for the submitted work. Financial relationships: All authors have declared that they have no financial relationships at present or within the previous three years with any organizations that might have an interest in the submitted work. Other relationships: All authors have declared that there are no other relationships or activities that could appear to have influenced the submitted work.

\section{Acknowledgements}

Dr. Harjeet Ghuman is hereby acknowledged for her assistance with the data collection component of the study.

\section{References}

1. Hameed SM, Brenneman FD, Ball CG, et al.: General surgery 2.0: the emergence of acute care surgery in Canada. Can J Surg. 2010, 53:79-83.

2. Gale SC, Shafi S, Dombrovskiy VY, Arumugam D, Crystal J: The public health burden of emergency general surgery in the United States: a 10-year analysis of the Nationwide Inpatient Sample-2001 to 2010. J Trauma Acute Care Surg. 2014, 77:202-208. 10.1097/TA.0000000000000362

3. Akinbami F, Askari R, Steinberg J, Panizales M, Rogers SO Jr: Factors affecting morbidity in emergency general surgery. Am J Surg. 2011, 201:456-462. 10.1016/j.amjsurg.2010.11.007 
4. Austin MT, Diaz JJ, Feurer ID, et al.: Creating an emergency general surgery service enhances the productivity of trauma surgeons, general surgeons and the hospital. J Trauma. 2015, 58:906-910. 10.1097/01.TA.0000162139.36447.FA

5. Ball, CG, Hameed SM, Brennemen FD: Acute care surgery: a new strategy for the general surgery patients left behind. Can J Surg. 2010, 53:84-85.

6. Faryniuk AM, Hochman DJ: Effect of an acute care surgical service on the timeliness of care . Can J Surg. 2013, 56:187-191. 10.1503/cjs.022911

7. Cubas RF, Gomez NR, Rodriguez S, Wanis M, Sivanandam A, Garberoglio CA: Outcomes in the management of appendicitis and cholecystitis in the setting of a new acute care surgery service model: impact on timing and cost. JACS. 2012, 215:715-721. 10.1016/j.jamcollsurg.2012.06.415

8. von Elm E, Altman DG, Egger M, Pocock SJ, Gøtzsche PC, Vandenbroucke JP: STROBE initiative. The strengthening the reporting of observational studies in epidemiology (STROBE) statement: guidelines for reporting observational studies. Lancet. 2007, 370:1453-1457. 10.1016/S0140-6736(07)61602-X

9. Clavien PA, Barkun J, de Oliveira ML, et al.: The Clavien-Dindo classification of surgical complications: fiveyear experience. Ann Surg. 2009, 250:187-196. 10.1097/SLA.0b013e3181b13ca2

10. Beardsley CJ, Sandhu T, Gubicak S, Srikanth SV, Galketiya KP, Piscioneri F: A model-based evaluation of the Canberra Hospital acute care surgical unit. Acute care surgery: a case of one size fits all?. Surg Today. 2014, 44:884-887. 10.1007/s00595-013-0775-2

11. Qureshi A, Smith A, Wright F, Brenneman F, Rizoli S, Hsieh T, Col Tien HC: The impact of an acute care emergency surgical service on timely surgical decision-making and emergency department overcrowding. JACS. 2011, 213:284-293. 10.1016/j.jamcollsurg.2011.04.020

12. Earley AS, Pryor JP, Kim PK, et al.: An acute care surgery model improves outcomes in patients with appendicitis. Ann Surg. 2006, 244:498-504. 10.1097/01.sla.0000237756.86181.50

13. Lau B, Difronzo LA: An acute care surgery model improves timeliness of care and reduces hospital stay for patients with acute cholecystitis. Am Surg. 2011, 77:1318-1321.

14. Lehane CW, Jootun RN, Bennett M, Wong S, Truskett P: Does an acute care surgical model improve the management and outcome of acute cholecystitis?. J Surg. 2010, 80:438-442. 10.1111/j.14452197.2010.05312.x

15. Milzman D, Soe-Lin H, Nyziorick K, et al.: Impact of acute care surgery service on timing of operation and outcome for emergency department diagnosis of appendicitis. Ann Emerg Med. 2010, 56:S102. 10.1016/j.annemergmed.2010.06.363

16. Wanis KN, Hunter AM, Harington MB, Groot G: Impact of an acute care surgery service on timeliness of care and surgeon satisfaction at a Canadian academic hospital: a retrospective study. World J Emerg Surg. 2014, 9:4. 10.1186/1749-7922-9-4

17. Vergis A, Metcalfe J, Stogryn S, Clouston K, Hardy K: The impact of acute care surgery on timeliness of care and patient outcomes: a systematic review of the literature. Can J Surg. 2019, 62:1-8.

18. Warnock GL: Dynamic growth of the acute care surgery model. Can J Surg. 2010, 53:76-77.

19. Golestanian E, Scruggs JE, Gangnon RE, Mak R, Wood K: Effect of interhospital transfer on resource utilization and outcomes at a tertiary care referral center. Crit Care Med. 2007, 35:1470-1476. 10.1097/01.CCM.0000265741.16192.D9

20. Rosenberg AL, Hofer TP, Strachan C, Watts CM, MD, Hayward RA: Accepting critically ill transfer patients: adverse effect on a referral center's outcome and benchmark measures. Ann Intern Med. 2003, 138:882-890. 10.7326/0003-4819-138-11-200306030-00009

21. Drake FT, Mottey NE, Castelli AA, et al.: Time-of-day and appendicitis: impact on management and outcomes. Surgery. 2017, 161:405-414. 10.1016/j.surg.2016.06.052

22. Crandall M, Shapiro MB, Worley M, West MA: Acute uncomplicated appendicitis: case time of day influences hospital length of stay. Surg Infect. 2009, 10:65-69. 10.1089/sur.2008.0004

23. Canadian Institute for Health Information. Better data. Better decisions. Healthier Canadians. Emergency department wait times in Canada continuing to rise. (2017). Accessed: May 5, 2017: https://www.cihi.ca/en/emergency-department-wait-times-in-canada-continuing-to-rise.

24. Bickell NA, Aufses AH Jr, Rojas M, Bodian C: How time affects the risk of rupture in appendicitis . J Am Coll Surg. 2006, 202:401-406. 10.1016/j.jamcollsurg.2005.11.016

25. Patel SS, Patel MS, Goldfarb M, Ortega A, Ault GT, Kaiser AM, Senagore AJ: Elective versus emergency surgery for ulcerative colitis: a National Surgical Quality Improvement Program analysis. Am J Surg. 2013, 205:333-338. 10.1016/j.amjsurg.2012.10.014

26. Abou-Nukta F, Bakhos C, Arroyo K, Koo Y, Martin J, Reinhold R, Ciardiello K: Effects of delaying appendectomy for acute appendicitis for 12 to 24 hours. Arch Surg. 2006, 141:504-507. 10.1001/archsurg.141.5.504

27. Eko FN, Ryb GE, Drager L, Goldwater E, Wu JJ, Counihan TC: Ideal timing of surgery for acute uncomplicated appendicitis. N Am J Med Sci. 2013, 5:22-27. 10.4103/1947-2714.106186

28. Bosk EA, Veinot T, Iwashyna TJ: Which patients and where: a qualitative study of patient transfers from community hospitals. Med Care. 2011, 49:592-598. 10.1097/MLR.0b013e31820fb71b

29. Ball CG, Dixon E, MacLean AR, Kaplan GG, Nicholson L, Sutherland FR: The impact of an acute care surgery clinical care pathway for suspected appendicitis on the use of CT in the emergency department. Can J Surg. 2014, 57:194-198. 10.1503/cjs.019912 